"Making the Blood Flow Backwards": Disability, Heterosexuality and the Politics of Representation in Julian Barnes's The Sense of an Ending

Dr Rachel Carroll

Teesside University

\begin{abstract}
In Julian Barnes's 2011 Man Booker Prize winning novel, The Sense of an Ending, the discovery of a forgotten letter prompts the narrator, Tony Webster, to reconsider the suicide of a brilliant school friend, Adrian Finn. The dramatic revelation of the existence of Finn's adult son (also called Adrian), borne of an extra-marital affair with his girlfriend's mother, is presented as offering a possible answer to the mystery of Finn's death. In this context, this article seeks to examine the representation of Finn's adult son as a person with a learning disability. In their book Narrative Prosthesis: Disability and the Dependencies of Discourse (2000), David T. Mitchell and Sharon L. Snyder critically examine the uses to which disability is put in narrative; this article will focus on the ways in which cognitive impairment is constructed in this novel. Depictions of disability in The Sense of an Ending will be situated within the context of representations of heterosexuality, reproductive sexuality and female sexuality; employing critical frameworks informed by both feminist and disability studies, this article will investigate the relationship between disability, maternal sexual transgression and discourses of normativity as represented in Barnes's novel.
\end{abstract}

Keywords: contemporary fiction; disability; learning disability; suicide; sexuality; heterosexuality; feminist theory; literary prizes. 


\section{"Making the Blood Flow Backwards": Disability, Heterosexuality and the Politics of Representation in Julian Barnes's The Sense of an Ending}

The critical reception of Julian Barnes's 2011 novel The Sense of an Ending was marked by a degree of discretion with regard to the dramatic revelation on which the novel hinges. Such discretion can be understood as reflecting a desire not to commit to print 'spoilers' which might impair the prospective reader's first encounter with this twist-ridden narrative. However, it could also be argued that this act of deference to authorial control served to foreclose discussion of a problematic representation. In Barnes's Man Booker Prize winning novel the dramatic revelation of a forgotten letter prompts the narrator, Tony Webster, to reconsider the suicide of a brilliant school friend, Adrian Finn, and forces him to confront the possibility of his own culpability. However, this revelation is followed by a series of dramatic disclosures which seem to overwrite the first, absolving Webster of blame by displacing it onto another cause. Finn is discovered to have an adult son, also called Adrian, borne of an extra-marital affair between the young Finn and his girlfriend's mother. In a novel which opens with the memory of a schoolboy's suicide following the discovery of his girlfriend's pregnancy, ${ }^{i}$ the revelation of an unwanted pregnancy is offered as a solution to the mystery of Finn's suicide. Implicit in the drama of this revelation is an assumption that the reader will accept that this man's existence can be seen as the probable cause of his father's suicide and as a signifier of his mother's sexual transgression. In this context how significant is it that Finn's adult son, Adrian, is depicted as a person with a disability? How significant is it that this disability concerns a cognitive impairment? In their book Narrative Prosthesis: Disability and the Dependencies of Discourse, David T. Mitchell and Sharon L. Snyder critically examine the uses to which disability is put in narrative. ii In this article, I aim to examine the way in which discourses of disability are mobilised in this novel - and to question the construction of disability as a marker of shame which arguably results. I will do so in part by situating depictions of disability in The Sense of an Ending within the context of representations of heterosexuality, reproductive sexuality and female sexuality. In its depiction of Adrian's disability as a direct consequence of mature motherhood, this narrative constructs older women's sexuality itself as abnormal and deviant. Unexpected narrative reversals are integral to the design of a novel whose title directly replicates that of Frank Kermode's seminal 1965 study of the same name. I will argue that in The Sense of an Ending the dramatic disclosure of Adrian's existence mobilises a retrospective logic by which recurring textual motifs of "damage"iii and "backward[ness]"iv converge in the construction both of his disability and his mother's sexual transgression.

\section{Barnes, the Man Booker and the construction of value}


The publication of Julian Barnes's novel, and its subsequent nomination for the 2011 Man Booker Prize, was met with almost universal critical approval within the review pages of the 'quality' broadsheet press. Some reservations were discreetly expressed about the novella's eligibility for an award for what the Man Booker Prize criteria describe as a "full-length novel", ${ }^{v}$ with critics seeking to make a virtue of its "brilliantly concise"vi and "brief but masterful"vii form. Elsewhere the rather cool, intellectual tone of Barnes's narrative conceits prompted some critics to suggest that the novel was more "clever than emotionally satisfying," viii with Christian House, writing in The Independent, proposing that Barnes "like his contemporaries, McEwan, Amis and Rushdie, is a ginand-tonic novelist: his books are crisp, cool and provide a kick to the head, but they seldom, as is the case here, touch the heart." ix However, an emerging critical consensus identified technical brilliance and philosophical sophistication as the novel's defining credentials and in doing so established a discourse of deference which prepared the way for a Man Booker Prize award which came to be seen not simply as success but rather as succession. A review of The Sense of an Ending published in The Observer newspaper in July 2011 in many ways typifies the discourses of reception which met its publication; Justin Cartwright wrote:

Deservedly longlisted for the Man Booker prize, this is a very fine book, skilfully plotted, boldly conceived, full of bleak insight into the questions of ageing and memory ... Barnes has achieved, in this shortish account of a not very attractive man, something of universal importance [emphasis added]. ${ }^{x}$

In recent years much critical attention has been given to the role of the literary prize in constructing canons of contemporary literary fiction. In The Economy of Prestige: Prizes, Awards and the Circulation of Cultural Value, James F. English argues that:

Institutionally, the prize functions as a claim to authority and an assertion of that authority the authority, at bottom, to produce cultural value. It provides an institutional basis for exercising, or attempting to exercise, control over the cultural economy, over the distribution of esteem and reward on a particular cultural field - over what may be recognized as worthy of special notice..$^{\mathrm{x}}$

Notably, English suggests that the annual controversies and scandals which attend the award of the Man Booker are integral to its success, arguing that the prize "is cultural practice in its quintessential contemporary form [emphasis in original]."xii From John Berger's denunciation of the neo-colonial politics of the Prize's agribusiness sponsors in 1972 to the Booker Prize Foundation's public penance for its failure - on four separate occasions - to recognise the achievement of the late Beryl Bainbridge, the Prize has thrived on the ritual retesting of its legitimacy, acted out on the pages of the quality print press and the screens of the broadcast media. The 2011 Prize was no exception. For those who suspect the Prize of elitism and complicity in a hierarchy of literary tastes, the inclusion of genre fiction in the 2011 shortlist was heartening. xiii However, others were appalled by the comments of the Prize panel Chair, Dame Stella Rimington, that "readability"xiv would be a key criteria. Indeed, in the days leading up to the award of the 2011 prize a number of leading contemporary authors were reported as backing the launch of a new prize, designed 
explicitly to reward literary merit in the face of what was seen as market-driven populism.

Rimington, former Director of MI5, opened her speech at the televised award ceremony with the following somewhat bruised aside: "I thought the intelligence world was the place for intrigue - but that was before I met the publishing world." Of course, Julian Barnes is no stranger to these tussles having been widely reported as dismissing the Prize as "posh bingo"xv when his Booker shortlisted novel Flaubert's Parrot failed to win in 1984. Three further nominations later - including England, England in 1998 and Arthur and George in 2005 - Barnes's acceptance speech at the illustrious Guildhall ceremony was characterised by an underlying sense of deferred entitlement. Declaring himself "as much relieved as I am delighted," he compared his plight as fourth time nominee to that of Jorge Luis Borges in relation to the Nobel Prize for Literature:

Borges, when asked as he continually was, why he'd never won the Nobel Prize, always used to reply that in Sweden there was a small cottage industry solely devoted to not giving Borges the Nobel Prize. And at times over the last years, in occasional moments of mild paranoia, I have wondered whether there wasn't perhaps some similar, sister organisation operating over here. ${ }^{\mathrm{xvi}}$

Moreover, Barnes was quoted backstage as admitting “I didn't want to go to my grave and get a Beryl",xvii a reference to the Best of Beryl reader's poll established by the Booker Prize Foundation as a rather patronising posthumous apology to Bainbridge, one of a number of women writers whose achievement has not been canonised by the Booker. As one of a generation of male novelists whose careers have dominated the contemporary literary fiction field since the 1980s including Amis, Ishiguro, McEwan and Rushdie, winner of the Booker of Bookers - it seems unlikely that Barnes would have suffered the same fate as Bainbridge. Indeed, the motif of the inevitability of Barnes's triumph in the 2011 prize assumed a self-fulfilling logic, with the exclusion from the shortlist of fellow (male) heavyweight contenders, such as Alan Hollinghurst's The Stranger's Child, seeming to clear the way for an uncontested succession.

In her book, Marketing Literature: The Making of Contemporary Writing in Britain, Claire Squires observes that "awarding a prize to a book acts not only to indicate value, but also to confer it."xviii The Booker Prize Foundation's strategies for prolonging media speculation over the outcome of its award - by publicly announcing first a long list and then a short list in advance of the actual award allows us to observe the discourses of canonisation in the making. Booker success is, of course, no guarantee of critical or commercial success but the persistent suspicion that the prize is sometimes awarded not so much to a novel as to a literary career is revealing of the role which the Man Booker has assumed in legitimising the work of specific authors. The convergence of critical consensus around The Sense of an Ending could be seen as symptomatic of this culture. I have prefaced my analysis of this novel with a sketch of the Man Booker prize context in order to highlight the cultural value (or "universal importance "xix) which this novel is now assumed to have in advance - such an assumption may act to inhibit readings which challenge the prevailing critical consensus on a novel which is, arguably, both complex and contentious. 


\section{"You just don't get it, do you?" Representing disability in The Sense of an Ending}

The succession of mysteries thrown up by the plot of The Sense of an Ending invite a deductive mode of reading which has prompted some critics to make analogies with genres of fiction not commonly associated with the Man Booker Prize. Barnes's novel has been compared not only to the detective fiction of Ruth Rendell|xx but also to the more sensational plotlines of Roald Dahl's short stories ${ }^{x x i}$ - in this way it is implicitly figured as a kind of upmarket 'tale of the unexpected.' However, a persistent and unresolved tension within the narrative complicates its capacity to deliver the kind of narrative resolution associated with such genres; this tension is embodied in the compromised narrative perspective of its narrator, Tony Webster. Central to the reader's doubts about the veracity of Webster's memory is his encounter with documentary evidence which confounds his own recollection of the past and his image of himself: namely, a letter written to Finn and Webster's former girlfriend Veronica on discovery of their relationship, which opens "Dear Adrian - or rather, Dear Adrian and Veronica (hello Bitch, and welcome to this letter)." $x x i i$ On rereading the letter Webster concedes:

I could scarcely deny its authorship or its ugliness. All I could plead was that I had been its author then, but was not its author now. Indeed, I didn't recognise that part of myself from which the letter came. But perhaps this was further self-deception.xxiii In a short space admission, denial and candour conspire to obscure the extent to which Webster has taken responsibility for this 'forgotten' letter and its consequences. His subsequent campaign to re-ingratiate himself with Veronica is suggestive both of a desire for conciliation and a desire to enlist her in the act of rewriting the past so as to erase the trace of his transgression:

What if by some means remorse can be made to flow backwards, can be transmuted into simple guilt, then apologised for, and then forgiven? What if you can prove you weren't the bad guy she took you for, and she is willing to accept your proof?xxiv Veronica's furious resistance to this campaign is encapsulated in an exasperated accusation, repeated on three different occasions: "'You just don't get it, do you? You never did, and you never will.'”xxv

Nevertheless, Webster's narrative does conclude with a revelation which prompts him to declare triumphantly: "And later, at home, going over it all, after some time, I understood. I got it."xxvi In a series of rapid deductions Webster constructs a "chain of responsibility"xxvii by which he becomes responsible not for the death of Finn but for the birth of a child with learning disabilities, and by which that child's disability becomes "time's revenge"xxviii both on his father's intellectual aspirations and his mother's sexual transgression. Whether the "it" which Webster has "got" is identical to the "it" which Veronica wishes him to deduce remains uncertain. However, Webster's pronouncement is here presented with the force of narrative resolution; in order to be accepted as such it must enlist the reader in consenting to the irrefutability of its logic. It is this logic which I now aim to unpick. 
In her essay "The Politics of Staring: Visual Rhetorics of Disability in Popular Photography,"

Rosemarie Garland-Thomson has argued that "the history of disabled people in the Western world is in part the history of being on display, of being visually conspicuous while politically and socially erased." "xxix She goes on to suggest that:

From antiquity through modernity, the bodies of disabled people considered to be freaks and monsters have been displayed by the likes of medieval kings and P.T Barnum for entertainment and profit in courts, street fairs, dime museums, and sideshows. Moreover, medicine has from its beginnings exhibited the disabled body as what Michel Foucault calls the "case", in medical theatres and other clinical settings, in order to pathologize the exceptional and to normalize the ordinary. $\mathrm{xxx}$

Garland-Thomson's thesis would seem most pertinent when applied to 'visible' as opposed to 'invisible' disabilities, such as cognitive impairments, and yet the language of spectacle is at the forefront of Webster's account of his first sight of Adrian and his companions. In a strong sense, the dramatic disclosure of Adrian's existence is reliant on his having been "politically and socially erased;" "xxi his status as Finn's son, and the familial and affective attachments that might have invited, having been implicitly concealed. Webster first encounters Adrian, his companions and their support workers in everyday public places, such as the residential neighbourhood, the supermarket and the pub, rather than in clinical or institutional settings. And yet Webster's gaze effectively places them "on display," "xxxii quickly establishing them as non-normative 'others':

I looked. A small group of people were coming along the pavement towards my side of the car. I counted five of them. In front was a man who, despite the heat, was wearing layers of heavy tweed, including a waistcoat and a kind of deerstalker helmet. His jacket and hat were covered with metal badges, thirty or forty of them at a guess, some glinting in the sun; there was a watch-chain slung between his waistcoat pockets. His expression was jolly: he looked like someone with an obscure function at a circus or fairground. Behind him came two men: the first had a black moustache and a kind of rolling gait; the second was small and malformed, with one shoulder much higher than the other - he paused to spit briefly into a front garden. And behind them was a tall, goofy fellow with glasses, holding the hand of a plump, Indianish woman." $x x x i i i$

Interestingly, it is only in relation to Adrian and his peers that raced constructions of identity are deployed in this novel. The "Indianish" woman and the care worker later identified as "a motherly black woman"xxxiv are the only characters categorised as non-white in this narrative set in contemporary Britain; discourses of race and disability here converge in a way which is not without historical precedent. $x \times x v$ Webster's use of nominally benign epithets to categorise the unnamed men - "the tweedy man . . . the lopsided fellow . . . the gangly chap"xxxvi - does not disguise a bemused condescension. Moreover, his allusion to the "circus or fairground" xxvvii places the group within the frame of the extraordinary and the freakish; this effect is compounded when he persists in this analogy: "The man with the badges - 'barker', that was the word l'd been looking for, the cheery fellow at the entrance to a fairground booth who encourages you to step inside and view the bearded lady or two-headed panda ... ."xxxviii However, following his discovery of Adrian's identity and parentage Webster inscribes him into a different narrative of disability. Webster's depiction of 
Adrian as a "poor damaged man"xxix whose birth has been the cause of first "sacrifice," then "terrible struggle" and finally "loss ... failure ... [and] guilt"xl on the part of his long-suffering mother conforms to predictable patterns where stereotypes of disability are concerned; his birth a tragedy, his life an affliction and his mother a martyr.

Garland-Thomson has identified what she calls "five narratives of disability" which, when considered together, constitute a typology of the uses of disability in narrative:

First is the biomedical narrative that casts the variations we think of as impairment as physiological failures or flaws, as medical crises that demand normalization through technology or other allopathic measures. Second is the sentimental narrative that sees people with disabilities as occasions for narcissistic pity or lessons in suffering for those who imagine themselves nondisabled. Third is the narrative of overcoming that defines disability as a personal defect that must be compensated for rather than as the inevitable transformation of the body that results from encounters with the environment. Fourth is the narrative of catastrophe that presents disability as a dramatic, exceptional extremity that either incites courage or defeats a person. Fifth is the narrative of abjection that identifies disability as that which one can and must avoid at all costs. ${ }^{x l i}$

Of these narrative types the sentimental narrative is at first most apparent in The Sense of the Ending, with Webster being moved to send a letter of conciliation and sympathy to Veronica, once vilified as an ex-girlfriend but now pitied as the assumed mother of a disabled adult son. Moreover, sobered by the life of tragic affliction which he has conjured for Adrian, Webster is prompted to count his blessings in terms which only reinforce the impression that life with a disability is inevitably a life of inferior value and meaning:

I thought more of Susie, and of the luck any parent has when a child is born with four limbs, a normal brain, and the emotional make-up that allows the child, the girl, the woman to lead any sort of life. May you be ordinary, as the poet once wished the new-born baby. ${ }^{\text {lii }}$ The possibility - indeed the reality - that life with a disability can be experienced within the spectrum of the 'ordinary' is precluded by this wish. Implicit in this sentimental narrative, however, is the narrative of abjection: the presumption that "disability [is] that which one can and must avoid at all costs"xliii is one which in some ways serves to retrospectively explain Finn's suicide. While Finn's suicide is presented as having occurred before his son's birth there is an insidious logic within the narrative which seems to suggest that being the father of a son with learning disabilities is a fate which Finn has "avoid[ed] at all costs" xliv through his suicide. Indeed, following the rediscovery of his malicious letter to Finn and Veronica, Webster conceives of Adrian's birth in terms of a curse fulfilled. While the younger Webster had written "'I hope you get so involved that the mutual damage will be permanent,"'xlv the adult Webster reflects on his hasty and hateful words as follows:

When l'd been trying to damage them, l'd written: 'Part of me hopes you have a child, because I'm a great believer in time's revenge.' . . . my words . . . seemed like some ancient curse I had forgotten even uttering. Of course I don't - I didn't - believe in curses. That's to say, in words producing events. But the very action of naming something that subsequently happens - of wishing specific evil, and the evil coming to pass - this still has a shiver of the otherworldly about it. xlvi 
The "specific evil" to which Webster refers here would seem to be Adrian and, more specifically, his disability.

While still labouring under the misapprehension that Adrian is Veronica's son, Webster infers a direct causal link between Veronica's suffering following Finn's suicide and her son's disability, such that Adrian becomes the external embodiment of Veronica's internal pain:

Now I had some answers to the questions I hadn't asked. She had become pregnant by Adrian, and - who knows? - perhaps the trauma of his suicide had affected the child in her womb. She had given birth to a son who had at some stage been diagnosed as ... what? xlvii $^{2}$

This causal logic - whereby disability is attributed to maternal abnormality - is also applied to the discovery that Adrian's mother is not Veronica, but her mother, Sarah Ford: "One born to a mother - 'The Mother' - at a dangerously late age. A child damaged as a result." xlviii Webster here draws a direct and unsupported causal link between maternal sexual transgression - in the form of a pregnancy following from an intergenerational sexual relationship - and disability. At this point I would like to place the representation of mature female sexuality and maternity in the context of representations of heterosexuality, reproductive sexuality and female sexuality in The Sense of an Ending. I will suggest that Webster's depiction of the sexuality of Veronica and Sarah Ford can be placed in a continuum framed by heteronormative imperatives; whereas Veronica's heterosexuality is constructed as the object of post Sixties male heterosexual entitlement, Sarah's mature reproductive sexuality is figured as transgressive and 'damaging'.

\section{“One born to a mother:" heterosexuality, reproductive sexuality and disability}

It has become a truism to observe that the Sixties - mythologised as a period of sexual liberation was experienced unevenly; indeed, this is a sentiment that Webster expresses with some bitterness than once. However, some of the paradoxes inherent in these discourses of sexual freedom are nevertheless manifest in Webster's account of denied sexual entitlement. It has been observed by many feminist commentators that while the increased availability of the contraceptive pill and the legalisation of abortion during this period extended the reproductive rights - and hence sexual freedoms - of many women, these same developments effectively absolved heterosexual men of responsibility for the reproductive consequences of heterosexual sexuality. Permitted only to consent to male heterosexual sexual access, women's attempts to exert sexual agency could then be dismissed as prudish, neurotic or manipulative. As Webster disingenuously complains:

And there was no arguing against 'feelings', because women were experts in them, men coarse beginners. So 'It doesn't feel right' had far more persuasive force and irrefutability than any appeal to church doctrine or a mother's advice. You may say, But wasn't this the Sixties? Yes, but only for some people, only in certain parts of the country. xlix

'Feelings' are here depicted as a ruse which women employ as a means to thwart male sexual freedom and to deny the heterosexual prerogatives which the Sixties had granted to men. Hence, 
Webster depicts intimate relationships between men and women in this period as a struggle for possession of territory, characterised by "bargain[s]," "trade-offs"li and "trade up[s]:"lii "Only when you were semi-publicly committed did you discover what her sexual policy might be. And sometimes this meant her body would be as tightly guarded as a fisheries exclusion zone." liii Their failure to have 'full sex' - defined in phallic terms by Webster as male penetration (Veronica's orgasms don't count) - is the source of a simmering resentment and hostility towards his girlfriend. These sentiments are given full and unedited expression in Webster's forgotten letter to Finn in which Veronica is denounced as a "cockteaser,"liv "stringing [Finn] along"|lv until she can entrap him through pregnancy. Webster's pathologising of Veronica has its origins in this letter in which he declares that "in my opinion Veronica had suffered damage a long way back." edits Veronica out of the sexual history he shares with his wife, but when he does disclose their past his version is sufficient to ensure that Margaret routinely refers to Veronica as "'The Fruitcake.'"lvii In this revisionary account of the sexual climate of Webster's youth, the gendered history of the Sixties is rewritten so that it is men - rather than women - who emerge as victims; indeed, in this novel it is the unmarried father, not the mother, who is driven to suicide by the stigma and shame of an unplanned pregnancy.

If Veronica's sexuality is depicted as deviant because it is withheld, her mother Sarah's is depicted as deviant because it is not; if Veronica's sexual agency is depicted as being the result of unspecified psychological "damage,"'|viii Sarah's is depicted as resulting in congenital "damage"lix in the form of an unspecified learning disability. Sarah's transgression is not depicted principally as one against marriage - the impact of her infidelity on her husband is not considered - but as a transgression against generation, both in terms of her intergenerational relationship with a younger man and in terms of her pregnancy as an older mother.

Sarah appears in two guises in The Sense of an Ending. Firstly as a mother in Webster's memory of his visit to Veronica's family home - or rather as "The Mother" as her bumptious Cambridge student son calls her, as if parodying the extent to which she fulfils the stereotypical role of middle class homemaker. In this role she seems more protective of her daughter's boyfriend than of her own daughter, warning him: "'Don't let Veronica get away with too much."'|x Her "somewhat artistic air"|xi might hint at a mildly bohemian tendency but her life is otherwise utterly conventional. She returns to the narrative in the guise of Mrs Sarah Ford, whose name and handwriting Webster is unable to identify when he first receives her bequest. The sum of money which she bequeaths to Webster in her will is the first of the mysteries to animate the second part of the narrative, but one which is never fully resolved; she herself admits that she is "not quite sure of my own motives."xii Webster interprets the legacy as a form of "maternal apology,"xiii integrating it into his narrative of injury at the hands of her daughter. Veronica's account of her life following her husband's death 
suggests an enjoyment of new found independence - "She did art classes, started smoking, and took in lodgers, even though she'd been left well provided for"lxiv - which is at odds with the life of tragic self-sacrifice which Webster had earlier imagined for the mother of a disabled child.

Gail H. Landsman refers to the "implicit assumption that the birth of a child with a disability requires the assignment of blame"|xv and examines the ways in which this blame often finds its target in the mother. The idea that the birth of a child with a disability can be read as a visible signifier of maternal transgression seems to revive archaic beliefs in "maternal impression." Ixvi As Rachel Adams has suggested:

Until the late eighteenth century, the concept of maternal impression held that pregnant women had the ability to imprint their unspoken fears and desires onto the fetal body. It was both a way of policing women by threatening that their crimes would become visible for all to see and an acknowledgement of the tremendous power they held over the reproductive process. Ixvii

However, the advent of late nineteenth and early twentieth century discourses of heredity and degeneracy saw the logic of cause and effect put to new disciplinary uses; in the context of the new 'science' of eugenics the birth of a child with a disability came to be seen as an outcome which could be controlled and which should be eliminated. Moreover, there is a complex relationship between the histories of women's reproductive rights in the same period and the civil rights of people with disabilities. In both the UK and the US leading female proponents of birth control and planned parenthood, such as Margaret Sanger and Marie Stopes, were also advocates of eugenics. Ixviii In more contemporary contexts, the development of new reproductive technologies has further complicated the relationship between feminism and disability rights: for example, Landsman suggests that the "birth of thousands of 'thalidomide babies', played an important role in the legalisation of abortion in the 1960s." Ixix Landsman and others propose that the advent of prenatal testing and the availability of selective abortion for foetuses deemed 'defective' has positioned women as custodians of normativity where disability is concerned. Both historical and contemporary discourses of disability seem to converge in Webster's rapid and decisive deduction on his discovery of Adrian, his disability and parentage; Adrian's difference is understood only in terms of 'damage' and his mother's non-normative sexuality constructed as its 'dangerous' cause. I wish to conclude by suggesting the ways in which this context - the legacy of eugenic discourses of heredity based on categories of intellectual ability- is pertinent when trying to make sense of the peculiar significance attributed to Adrian's cognitive impairment in the narrative structure of Barnes's novel.

\section{"Making the blood flow backwards": the ends of disability in The Sense of an Ending}

Webster's deduction about Adrian's parentage represents his solution to the mysterious formulas which appear in Finn's diary, bequeathed to Webster in Sarah Ford's will. Indeed, it is interesting to note that Finn's attempt to express interpersonal relationships in the form of a mathematic 
formula is not seen as indicative of a deficit in emotional intelligence but rather as symptomatic of his exceptional intellect. Webster is scornful of his mother's attempt to attribute Finn's suicide to his abnormal cleverness, but he and his former school friends arrive at the same conclusion: "Firstclass degree, first-class suicide."'lxx Selective, but meritocratic, education is the governing principle which underlines the belief in gradual but inevitable social betterment which informs the lives of Webster, his school peers and their families, or as he puts it "the genteel social Darwinism of the English middle classes." "xxi In this narrative context the prospect of reversion is presented as disturbingly unnatural.

The image of a river running upstream, witnessed by Webster as a student at the annual tidal bore on the River Severn, serves as a key textual motif within The Sense of an Ending: "It was more unsettling because it looked and felt quietly wrong, as if some small lever of the universe had been pressed, and here, just for a few minutes, nature was reversed, and time with it."|xxii This is one of the memories, both direct and indirect, with which the novel opens and in which intimations of the sexual and the unnatural converge; the tidal waters of the Severn "rushing nonsensically upstream"|xxiii are evoked alongside the "shiny inner wrist" |xxiv and "gouts of sperm circling a plughole" Ixxv which signify the unspoken terms of Webster and Veronica's sexual relationship, the "bathwater long gone cold" |xxvi into which Finn opens his wrists and the "steam rising from a hot sink" "xxvii as Sarah Ford discards a broken egg in a scene retrospectively infused with coded sexual meaning. Indeed, the narrative itself follows a pattern of reversion. Coming to a premature and rather listless halt at the end of the first part, in the second it reverts to the past once more as the rush of new revelations forces Webster to revisit his memories: "I thought - at some level of my being, I actually thought - that I could go back to the beginning and change things. That I could make the blood flow backwards." "|xviii Webster's futile attempts to make time and memory "flow backwards"||xxix is coupled with an apprehension that such an endeavour is somehow against nature: "So when this strange thing happened - when these new memories suddenly came upon me - it was as if, for that moment, time had been placed in reverse. As if, for that moment, the river ran upstream." "|xxx Webster's discovery of Adrian and of his disability seems somehow implicated in this discourse of reversion; indeed, it prompts Webster to reconsider his estimation of Finn, now revealed as Adrian's father. A swift narrative sleight of hand at the conclusion of this novel seems to invite us to consider Adrian's cognitive disability as serving the function of a dramatic irony visited on the memory of his father. In this literary 'tale of the unexpected' Adrian's disability is offered, it seems, as a kind of intellectual joke at Finn's expense. But it is Adrian - and more broadly the figure of the person with learning disabilities - with whom I am concerned here. The juxtaposition of Finn's exceptional intellect with Adrian's learning disability seems designed to deliver a decisive narrative irony; as the standard bearer for the ascendency of high order abstract 
thought Finn is implicitly undone by fathering a child whose cognitive abilities are constructed in inferior and negative terms.

It is the coercive logic of this deduction which I have tried to unpick in my analysis of the representational strategies at work in this narrative. This novel contains many uneasy or uncomfortable moments arising from Webster's often unsympathetic point of view. However, where those concerning Veronica are later qualified by Webster's candid admissions of error or bias, those concerning Adrian remain uncontested. It is evident that Webster's narrative perspective is not offered as unproblematic; indeed, his attitudes to disability could be attributed to his personality traits (including pride, self-interest and insensitivity to others) as a character who is very much a product of his culture (in terms of gender, class, ethnicity, education and generation). However, the narrative function of disability in relation to the structural and thematic design of the novel is less easy to dismiss. In her book The Faces of Intellectual Disability: Philosophical Reflections, Licia Carlson examines the way in which intellectual disability has been used in philosophical discourse as a kind of limit case against which to test the personhood of non-disabled people, and indeed the rights of non-human animals. Adrian seems to serve a similar function in The Sense of an Ending and his personhood is arguably forfeited as a result. Leading scholars in the field of disability studies, including Lennard J. Davis, have demonstrated the necessity of interrogating not simply the discourses of disability but also the discourses of normalcy - and the way in which the latter depend on the former. In this way, questions to do with disability become integral, rather than marginal, to all critical endeavours within the humanities. ${ }^{\text {Ixxi }}$ In my reading of The Sense of an Ending I have sought to take what might seem a marginal representation of disability and tried to make visible the ways in which this disability is the product of dominant discourses of normalcy to do with both intellect and sexuality - discourses which impact on all bodies and identities. As Davis states in his book Enforcing Normalcy:

... disability is not a minor issue that relates to a relatively small number of unfortunate people; it is part of a historically constructed discourse, an ideology of thinking about the body under certain historical circumstances. Disability is not an object - a woman with a cane ["the tweedy man ... the lopsided fellow ... the gangly chap"||xxii] - but a social process that intimately involves everyone who has a body and lives in the world of the senses. ${ }^{\mid \mathrm{x} x \mathrm{iii}}$ [Emphasis added]

\footnotetext{
i "Robson [Webster's classmate] had got his girlfriend pregnant, hanged himself in the attic, and not been found for two days." Julian Barnes, The Sense of an Ending (London: Jonathan Cape, 2011), p. 13.

ii "Our thesis centers not simply upon the fact that people with disabilities have been the object of representational treatment, but rather that their function in literary discourse is primarily twofold: disability pervades literary narrative,
} 
first, as a stock feature of characterization and, second, as an opportunistic metaphorical device." David T. Mitchell and Sharon L. Snyder, Narrative Prosthesis: Disability and the Dependencies of Discourse (Ann Arbor: University of Michigan Press, 2000), p. 47.

iii Barnes, p. 5, p. 42, p. 44, p. 96, p. 138, p. 139 and p. 149.

iv See Barnes, p. 36, p. 107, p. 122 and p. 130.

v The Man Booker Prize website, http://www.themanbookerprize.com/entering-the-awards [Date accessed: 13.5.2013].

vi Justin Cartwright. "The Sense of an Ending by Julian Barnes - review" The Observer, Sunday 31 July 2011. http://www.guardian.co.uk/books/2011/jul/31/sense-ending-julian-barnes-review. [Date accessed: 29.10.12].

vii Anita Brookner, "The Sense of an Ending: review", The Telegraph, 25 July 2011.

http://www.telegraph.co.uk/culture/books/bookreviews/8652283/The-Sense-of-an-Ending-by-Julian-Barnesreview.html. [Date accessed: 29.10.12].

viii Michiko Kakutani, "Life in Smoke and Mirrors," The New York Times, 16 October 2011.

http://www.nytimes.com/2011/10/17/books/Julian-Barness-Sense-of-an-Ending-Review.html. [Date accessed: 29.10.12].

ix Christian House, “The Sense of an Ending, by Julian Barnes” The Independent, Sunday 7 August 2011.

http://www.independent.co.uk/arts-entertainment/books/reviews/the-sense-of-an-ending-by-julian-barnes-

2333068.html. [Date accessed: 29.10.12].

$\times$ Cartwright.

xi James F. English, The Economy of Prestige: Prizes, Awards and the Circulation of Cultural Value (Cambridge,

Massachusetts; London, England: Harvard University Press, 2005), p. 51.

xii English, p. 26.

xiii The 2011 Man Booker shortlist included Patrick DeWitt's Western-inspired The Sisters Brothers and A.D Miller's thriller Snowdrops.

xiv For a full transcript of Dame Stella Rimington's speech at the 2011 Man Booker Prize award ceremony, 2011 see: http://www.themanbookerprize.com/feature/dame-stella-rimington\%E2\%80\%99s-speech-man-booker-prize-2011 [date accessed: 13.5.2013].

xv Julian Barnes, "Diary," London Review of Books 9.20 (1987): 21. http://www.lrb.co.uk/v09/n20/julian-barnes/diary [Date accessed: 13.5.13].

xvi Julian Barnes, 2011 Man Booker Prize acceptance speech. http://www.bbc.co.uk/news/entertainment-arts-15361059

[Date accessed: 13.5.13].

xvii Mark Brown, "Booker prize 2011: Julian Barnes triumphs at last"

http://www.guardian.co.uk/books/2011/oct/18/booker-prize-julian-barnes-wins

[Date accessed: 13.5.13].

xviii Claire Squires, Marketing Literature: The Making of Contemporary Writing in Britain (London: Palgrave Macmillan, 2009), p. 97.

xix Cartwright.

xx See House.

xxi See Justine Jordan, “The Sense of an Ending by Julian Barnes - review," The Guardian, Tuesday 26 July 2011. http://www.guardian.co.uk/books/2011/jul/26/sense-ending-julian-barnes-review1 [Date accessed: 13.5.13].

xxii Barnes, p. 95.

xxiii Barnes, p. 97.

xxiv Barnes, p. 107.

xxv Barnes, p. 126. See also p. 100 and p. 144.

xxvi Barnes, p. 148.

xxvii Barnes, p. 149.

xxviii Barnes p. 139.

xxix Rosemarie Garland-Thomson "The Politics of Staring: Visual Rhetorics of Disability in Popular Photography,"

Disability Studies: Enabling the Humanities, ed. Sharon L. Snyder, Brenda Jo Brueggemann and Rosemarie Garland-

Thomson (New York: Modern Languages Association of America, 2002), p. 56.

xxx Garland-Thomson, p. 56.

xxxi Rosemarie Garland-Thomson "The Politics of Staring: Visual Rhetorics of Disability in Popular Photography," p. 56.

xxxii Rosemarie Garland-Thomson "The Politics of Staring: Visual Rhetorics of Disability in Popular Photography," p.

56.

xxxiii Barnes, pp. 124-5.

xxxiv Barnes, 35.

xxxv In Enforcing Normalcy: Disability, Deafness and the Body (London: Verso, 1995), Lennard Davis has argued that what he calls the "social process of disabling arrived with industrialization and with the set of practices and discourses 
that are linked to late eighteenth- and nineteenth-century notions of nationality, race, gender, criminality, sexual orientation, and so on"(p. 24). He goes on to argue that applications of Darwin's theories of evolution in the late nineteenth "serve[d] to place disabled people along the wayside as evolutionary defectives to be surpassed by natural selection" (p. 31). Eugenics, a movement which attracted a following of respected intellectuals in both Britain and the US in the first decades of the twentieth century, made category analogies between non-white and disabled people as representing lower levels of evolutionary development; these discourses, with their preoccupation with heredity and degeneracy, conspire to construct the birth of a disabled or mixed race child alike as a cause for dismay and an object of state intervention. Indeed, disabled people and non-white people have historically been the victims of eugenic policies, ranging from forced sterilisations to genocide.

xxxvi Barnes, p. 127.

xxxvii Barnes, pp. 124-5.

xxxviii Barnes, pp. 126-7.

xxxix Barnes, p. 139.

xl Barnes, 139.

xli Garland-Thomson, “Feminist Disability Studies," Signs: Journal of Women in Culture and Society 30:2 (2005): 1557-87, pp. 1567-8.

xlii Barnes, p. 144.

xliii Garland-Thomson, “Feminist Disability Studies," pp. 1568.

xliv Garland-Thomson, "Feminist Disability Studies," pp. 1568.

xlv Barnes, p. 95.

xlvi Barnes, p. 138

xlvii Barnes, p. 139.

xlviii Barnes, p. 149.

xlix Barnes, p. 23.

${ }^{1}$ Barnes, p. 26.

li Barnes, p. 22.

lii Barnes, p. 41.

liii Barnes, p. 22.

liv Barnes, p. 96.

lv Barnes, p. 41.

Ivi Barnes, p. 42.

lvii Barnes, p. 74 .

lviii Barnes, p. 95 and p. 96.

lix Barnes, p. 149.

1x Barnes, p. 28.

lxi Barnes, p. 27.

lxii Barnes, p. 65.

lxiii Barnes, p. 64 .

lxiv Barnes, p. 111.

${ }^{1 \times v}$ Gail H. Landsman, "Reconstructing Motherhood in the Age of 'Perfect' Babies: Mothers of Infants and Toddlers with Disabilities," Signs 24:1 (1998): 69-99, p. 95.

Ixvi Rachel Adams, Sideshow USA: Freaks and the American Cultural Imagination (Chicago: University of Chicago Press, 2001,) p.187.

lxvii Adams, p. 187.

Ixviii As Licia Carlson notes: "There are numerous historical examples of early feminists building cases for women's reproductive freedom and rights that explicitly employed eugenic rhetoric regarding the undesirability of 'feebleminded offspring,' thereby drawing a sharp line between 'normal' women deserving of reproductive autonomy, and 'defective' women who should not be allowed to reproduce more of their kind." The Faces of Intellectual Disability (Bloomington: Indian University Press, 2010), pp. 175-6.

lxix Landsman suggests that the "the avoidance of disability remains an important factor in the continued use and regulation of abortion" (p. 79).

Ixx Barnes, p. 140.

lxxi Barnes, p. 8.

lxxii Barnes, p. 36.

lxxiii Barnes, p. 3.

lxxiv Barnes, p. 3.

lxxv Barnes, p. 3.

lxxvi Barnes, p. 3. 
lxxvii Barnes, p. 3.

lxxviii Barnes, p. 130.

lxxix Barnes, p. 107.

Ixxx Barnes, p. 122.

Ixxi Rosemarie Garland Thomson argues that "Disability studies should become a universalising discourse in the way that Sedgwick imagines gay studies and feminism to be. Disability (or gender or homosexuality) would then be recognised as structuring a wide range of thought, language, and perception that might not be explicitly articulated as "disability."" Extraordinary Bodies: Figuring Physical Disability in American Culture and Literature (New York: Columbia University Press, 1997), p. 22.

Ixxxii Barnes, p. 127.

lxxxiii Davis, p. 2. 